\title{
A STUDY ON THE IMPROVEMENT OF A LOCAL BOTTLE MANUFACTURING OPERATION: DEPLOYMENT OF LEAN PRINCIPLES AND DISCRETE EVENT SIMULATION
}

\author{
Ezekiel Yorke $^{1 *}$, Boppana V. Chowdary ${ }^{2}$ and Jainarine Bansee ${ }^{3}$ \\ ${ }^{1,2,3}$ Faculty of Engineering, The University of the West Indies, Trinidad \\ ${ }^{1}$ Email: ezekiel_yorke@hotmail.com* \\ ${ }^{2}$ Email: boppana.chowdary@sta.uwi.edu \\ ${ }^{3}$ Email: jainarine_bansee@yahoo.com
}

\begin{abstract}
Local manufacturing small and medium enterprises (SME) have faced continuous challenges in competing with manufacturing firms of scale on the global market. Factors such as the presence of a traditional organisational structure and inefficient utilisation of resources have contributed to the challenges faced by local SMEs in keeping up with regional and international competitors within the manufacturing sector. To investigate the aforementioned challenges, a case study was conducted on a local bottle manufacturing SME which sought to improve their system performance across their Plastic Injection Melding (PIM) operation. Using strategies in the form of lean manufacturing as well as ARENA $®$ simulation software, the challenges identified within their operation were observed and mitigated using key performance indicators. Lean strategies such as Heijunka, Kanban and Six Sigma were utilised as possible methods of reducing waste within the existing simulation model. When comparing the key performance indicators from the simulation, findings highlighted improvements in the Work in Process (WIP) and Waiting Time (WT) by $84.78 \%$ and $98.03 \%$ for the entire operation. A cost-benefit analysis was carried out to identify the most financially feasible strategy in purchasing the resources that were required for the strategy's integration into the actual system.
\end{abstract}

Keywords: Discrete event simulation, Key performance indicators, Lean manufacturing, Plastic injection moulding, Small and medium enterprise.

https://doi.org/10.47412/HQCS4121

\section{Introduction}

Manufacturing has been deemed one of the engines of economic and social growth for countries among the global markets. Within the bottling industry, improved manufacturing processes have played pivotal roles in improving productivity and delivery of new products and services by incorporating intellectual properties such as product design, integrated manufacturing technology, production planning along with many other factors across various multi-disciplinary manufacturing industries [12]. For smaller regions such as Trinidad and Tobago (T\&T), manufacturing within the bottling industry has dominantly been deemed a Small and Medium Enterprise (SME) [15]. However, local manufacturers over recent years have begun to experience challenges due to increasing competitive levels from foreign markets [16]. In light of this, this research was used to present a computer integrated simulated approach through ARENA ${ }^{\circledR}$ in order to highlight some of the required factors needed by local SMEs to remain competitive in the global market. 


\section{Literature Review}

The injection moulding process, despite having obtained established standards and practices continues to facilitate room for improvement in quality and stability of the processes involved as well as the products produced [23]. Factors that were quite dynamic such as temperature, pressure and polymer quality of the raw materials in the case of PIM have required newer and more intricate methods of being carefully monitored to ensure maximum output quality of plastic products. As a result, improvements using general frameworks of real world processes have continued to be formulated for meeting the challenges that exist during PIM, which include better defect detection and delayed processing times. The parameters involved within PIM operations have been key, in the eyes of researchers to derive optimal methods in formulating solutions for maximizing the performance of PIM [6]. Research also identified the need to incorporate methods of improvement such as artificial neural networking and Particle Swarming Optimisation (PSO), along with facets of Taguchi method as a lean principle in cases where conceptual frameworks were unable to satisfy the challenges faced [5][22]. Additionally, researchers have turned to simulation to quantify the challenges faced in the industry.

Solution through simulation using ARENA ${ }^{\circledR}$ as a tool for improving manufacturing processes has seen success in various manufacturing disciplines. Based on the case studies that were used to highlight current trends of Discrete Event Simulation (DES) and manufacturing, it was evident that solution through simulation using ARENA® was a viable tool for improving Plastic Injection Moulding (PIM) operations in the bottle manufacturing industry [4].

To further emphasise the benefits of ARENA ${ }^{\circledR}$ simulation for manufacturing SMEs, the following examples were presented. In a case study, Kumar et al. highlighted improvements to the facility and process layout of a manufacturing SME in the automotive parts sector [13]. The overall aim of the company was geared towards improving productivity through the use of Key Performance Indicators (KPI) such as Value Added Time (VAT), Non-Value Added Time (NVAT), Cost, Throughput (TP), Capacity Utilisation (CU), Waiting Time (WT) and Work-in-Process (WIP). From the results observed, TP per month increased from 1200 units to 1700 units, which resulted in a $37.5 \%$ with a decreasing in WT. Another related example included the improvement in productivity within a food processing plant of $50 \%$ in TP with a decrease of $11.4 \%$ in average manufacturing time [1]. However, in order to satisfy the requirements for optimizing these operations in the industry, lean thinking strategies in the form of Lean Manufacturing have also been used as philosophical approaches for improving manufacturing processes and systems.

Lean Manufacturing (LM) was notably developed from early practitioners in the Toyota Production System after the second world war in Japan [21] and experienced many evolutions to meet the demands of manufacturers of various levels of scale. Results highlighted from various case studies presented challenges with respect to the ease of implementation of LM into SMEs while revealing the solutions to tackling the aforementioned barriers [17]. Drivers such as financial benefits along with waste reductions supported earlier suggestions where intangible barriers, despite the different regions in which SMEs existed were able to be challenged through statistical means in order to encourage the integration of lean manufacturing practices. This gap in the form of intangible barriers as aforementioned existed in the areas of nonfamiliarity to lean thinking, organisational culture, assumptions that LM was not possible in the company along with many others. This therefore supported the theory where using solution through simulation such as ARENA® to illustrate the results of LM in the company's manufacturing process provided much benefit with minimum challenge in the statistical region by intangible barriers as mentioned in this research [18].

\section{A Case Study}

\subsection{System Logic}

A local bottle manufacturing company was seeking ways to improve their plastic injection moulding (PIM) process. This process was responsible for the first stage of manufacturing their plastic bottle products. This stage of manufacturing was shifting to a semi-automatic structure to improve productivity. However, based 
on feedback obtained from Quality Control and one of the senior technicians on the plant, it was revealed that the injection moulding process was not functioning at maximum performance to satisfy this continuous shift. Three major challenges which prohibited this task were subsequently identified: The reduction in system performance due to one of the company's aging PIM machines; increasing the volume of inspected products without incurring substantial Waiting Time (WT) and Work in Process (WIP); inefficient Capacity Utilisation (CU) of one of the company's PIM machines. In lieu of these findings, the overall aim of the company was geared towards improving productivity through the use of Key Performance Indicators, some of which were aforementioned.

\subsection{Brief Description of the Existing System}

The manufacturing flow layout in Fig. 1 of the injection moulding process was used in designing the simulation models to reflect the actual PIM operations. Upon visiting the manufacturing plant, data was collected for various processes. Two categories of raw material, P1 and P2 were documented along with the inter-arrival times (IAT) between each manufacturing cycle. The number and type of resources used for each process were also recorded. In addition, the injection moulding machines utilised different processing times (PT) for P1 and P2 respectively. Thus, the PT for each raw material was collected, which included the times for the injection moulding processes, conveyor transfer processes as well as the inspection processes over a period of ten manufacturing cycles, Table 8.

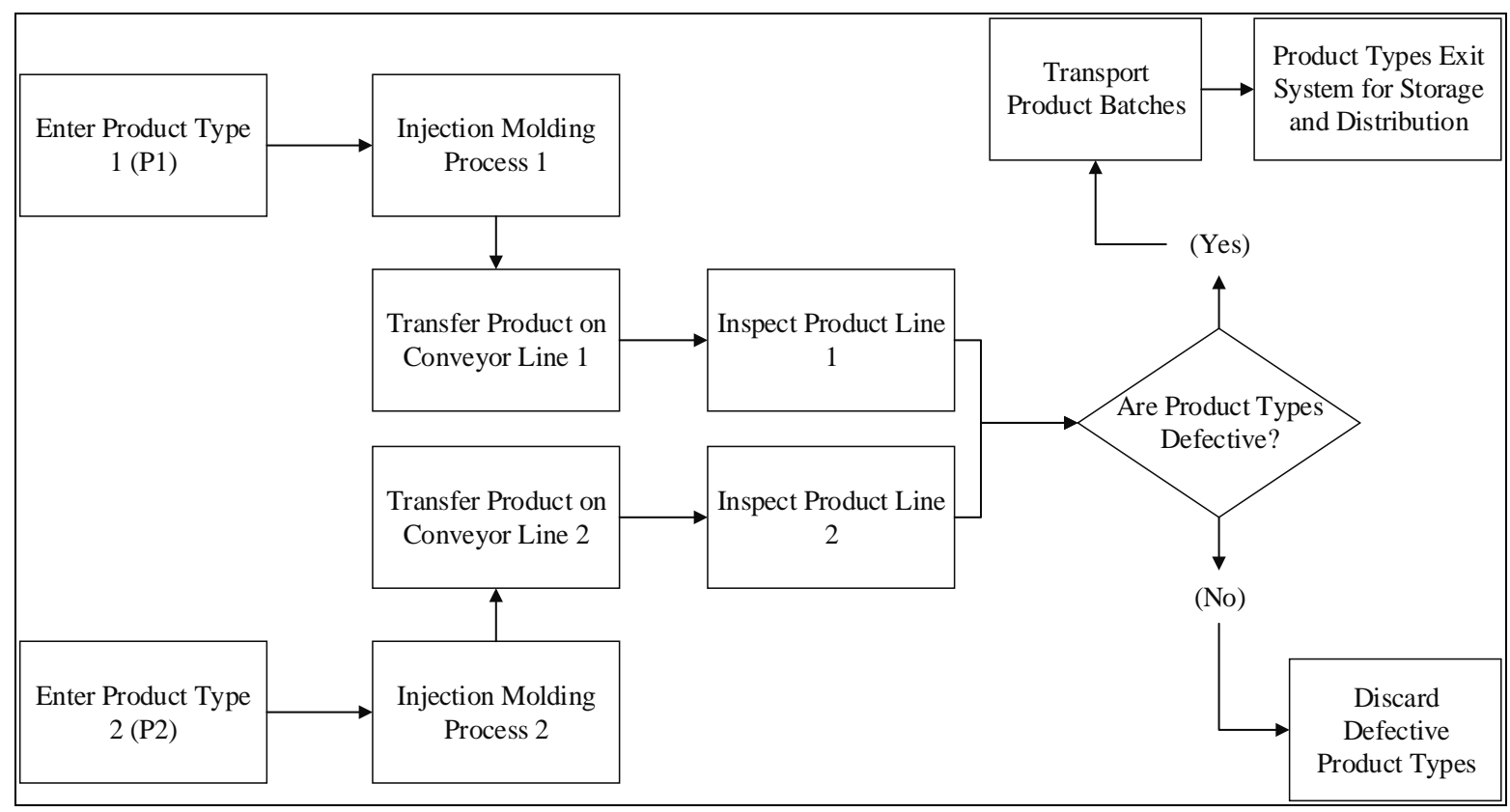

Figure 24: Flow of the PIM Operations. 
Table 8: Raw Data of Processes and Processing Times.

\begin{tabular}{|c|c|c|c|c|c|c|c|c|c|c|}
\hline \multirow{2}{*}{ Process Name } & \multicolumn{10}{|c|}{ Processing Time (PT) [seconds] } \\
\hline & PT 1 & PT 2 & PT3 & PT 4 & PT 5 & PT 6 & PT 7 & PT 8 & PT 9 & PT 10 \\
\hline $\begin{array}{c}\text { IAT of Product } \\
\text { Type 1A }\end{array}$ & 4.44 & 4.59 & 4.60 & 4.43 & 4.50 & 4.48 & 4.58 & 4.62 & 4.45 & 4.40 \\
\hline $\begin{array}{l}\text { IAT of Product } \\
\text { Type 1B }\end{array}$ & 4.44 & 4.59 & 4.60 & 4.43 & 4.50 & 4.48 & 4.58 & 4.62 & 4.45 & 4.40 \\
\hline $\begin{array}{c}\text { LAT of Product } \\
\text { Type } 2 \mathrm{~A}\end{array}$ & 4.44 & 4.59 & 4.60 & 4.43 & 4.50 & 4.48 & 4.58 & 4.62 & 4.45 & 4.40 \\
\hline $\begin{array}{c}\text { LAT of Product } \\
\text { Type } 2 \mathrm{~B}\end{array}$ & 4.44 & 4.59 & 4.60 & 4.43 & 4.50 & 4.48 & 4.58 & 4.62 & 4.45 & 4.40 \\
\hline $\begin{array}{c}\text { Injection } \\
\text { Moulding } \\
\text { Process 1A }\end{array}$ & 5.43 & 5.84 & 5.31 & 4.85 & 5.19 & 5.13 & 4.41 & 4.52 & 4.73 & 4.99 \\
\hline $\begin{array}{l}\text { Injection } \\
\text { Moulding } \\
\text { Process 1B }\end{array}$ & 6.41 & 5.82 & 6.21 & 5.89 & 6.34 & 5.98 & 5.54 & 6.29 & 5.83 & 5.32 \\
\hline $\begin{array}{c}\text { Injection } \\
\text { Moulding } \\
\text { Process 2A }\end{array}$ & 9.43 & 9.84 & 9.31 & 8.85 & 9.19 & 9.13 & 8.41 & 8.52 & 8.73 & 8.99 \\
\hline $\begin{array}{c}\text { Injection } \\
\text { Moulding } \\
\text { Process 2B }\end{array}$ & 12.41 & 11.82 & 12.21 & 11.89 & 12.34 & 11.98 & 11.54 & 12.29 & 11.83 & 11.32 \\
\hline $\begin{array}{l}\text { Convey Product } \\
\text { for Inspection } \\
\text { Line } 1\end{array}$ & 4.23 & 3.83 & 3.98 & 3.90 & 3.90 & 4.39 & 4.09 & 3.90 & 3.43 & 4.54 \\
\hline $\begin{array}{c}\text { Convey Product } \\
\text { for Inspection } \\
\text { Line } 2\end{array}$ & 5.30 & 5.02 & 4.43 & 4.01 & 5.29 & 5.03 & 4.90 & 4.49 & 4.90 & 4.91 \\
\hline $\begin{array}{l}\text { Inspect Product } \\
\text { Line } 1\end{array}$ & 10.24 & 5.76 & 13.76 & 7.04 & 16.96 & 11.2 & 12.16 & 19.52 & 8.64 & 6.08 \\
\hline $\begin{array}{c}\text { Inspect Product } \\
\text { Line } 2\end{array}$ & 14.12 & 9.72 & 17.64 & 11.04 & 20.72 & 15.00 & 15.88 & 23.80 & 12.36 & 10.16 \\
\hline $\begin{array}{c}\text { Transport } \\
\text { Product Types } 1 \\
\text { and } 2 \text { Batches }\end{array}$ & 1.46 & 1.67 & 1.92 & 1.48 & 1.76 & 2.09 & 1.79 & 1.56 & 1.58 & 2.03 \\
\hline
\end{tabular}

\section{Development of the Simulation Model}

A simulation model was developed using data obtained from the PIM operations. Since a continuous runtime was needed so as to eliminate any errors within the system, a steady state simulation was chosen [10]. Figure 2 showed the model that was used for simulating the PIM operations. By documenting the schedule for products P1 and P2, simulation results were obtained over a one month, six months and twelve-month period. These periods were chosen so as to observe any potential trends in the performance of the PIM operations using the aforementioned KPI. The warm-up period used was eight hours. This value was chosen due since each working shift comprised of 8 hours, and thus, duties and operations would have already begun to meet the production demand of the plant. 


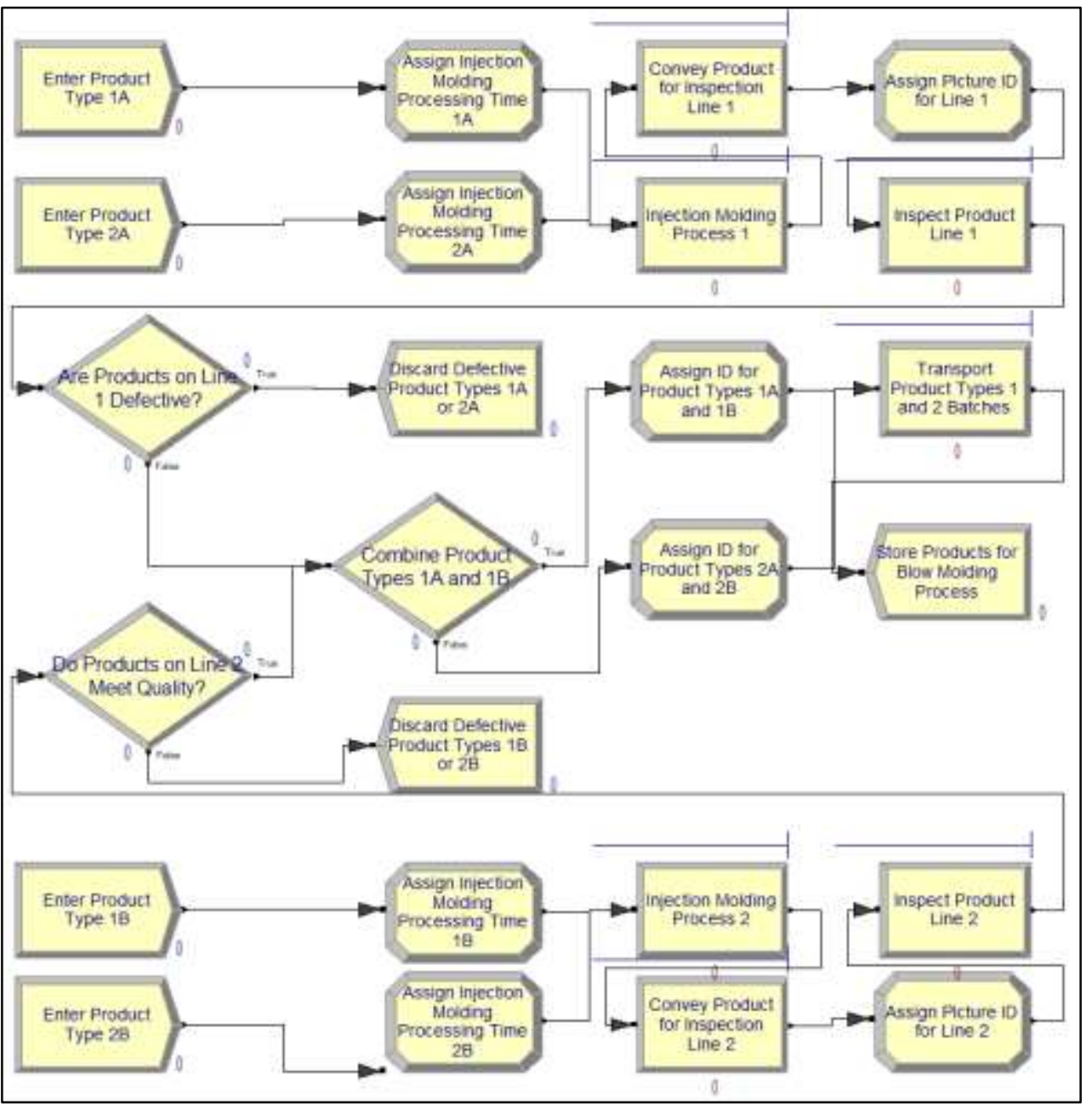

Figure 25: Simulation Model of Existing PIM System.

\subsection{Validation of the Simulation Model}

To validate the model, constant values using the PT AVG data were used for each of the processes in order to confirm that the total processing time along with other statistics mirrored the PT of the actual system's PIM operations [7]. When this was completed, the PT AVG times were replaced with calculated distributions of their respective constant values, as highlighted in Fig. 3 to complete the validation of the inputted data. Hence, using the input analyser within ARENA®, the distributions of each process was generated using the algorithms built into the simulation software.

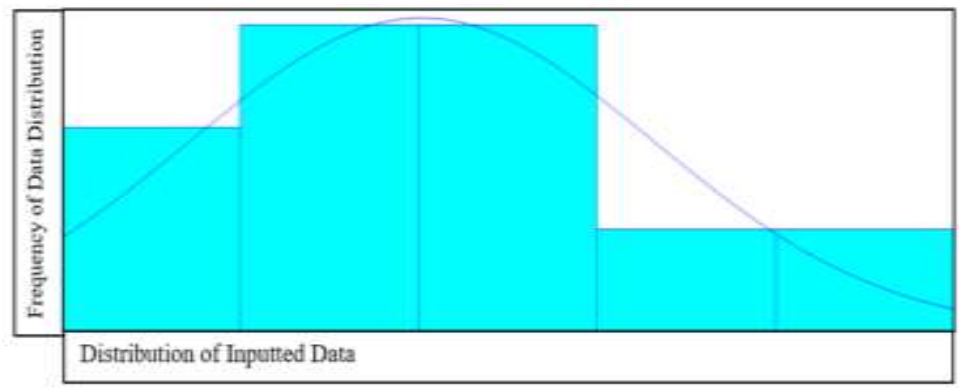

Figure 26: PT Distribution of Injection Moulding Process 1A. 


\subsection{Model Assumptions}

The following highlighted the assumptions of the research:

- The simulation models were developed based on the assumption that the technicians remained at their assigned processes constantly for the entirety of their shifts.

- Since it was assumed that the cost of labour for each technician was the same, the technicians that were assigned to each process persisted throughout the entire simulation lengths.

- The cost to operate the forklift during the Transport Product Type process was calculated using typical values obtained from secondary sources. The final costs that were used in the simulation models were calculated to mirror the total operational cost per hour over a period of twelve months [19].

- Similar to that of mould changeover times, setup time for the injection moulding processes each week incurred minimal NVAT since the PIM machines operated continuously until the end of the work week.

\subsection{Research Limitations}

The limitations in this research were as follows:

- The information on an accurate cost of labour regarding the technicians was unable to be directly received from the company due to confidentiality. Thus, a typical value of $\$ 40$ per hour was used [8].

- Since ARENA® Student was unable to facilitate a 1:1 ratio of entities entering and leaving the simulation model, numerical scaling using MATLAB was used due to sheer volume of numerical data. Hence, the KPI used in this research simulation did not $100 \%$ mirror the actual system performance on a true 1:1 scale. To account for this, each simulation was run using ten replications, after which data was tabulated for a one-month, six-month and twelve-month period.

- Due to reasons of confidentiality, some financial information was unobtainable to account for the costs incurred by the resources during the simulations. These included hourly operation costs for the injection moulding machines, total labour cost per hour for each allocated technician and the prices of each machines at the time of their purchase. Thus, values typical of the operational cost per hour for these resources were obtained using a secondary reference [2].

\section{Analysis of Findings of the Existing Simulation}

After running the simulations for the subsequent periods, the KPI revealed an increasing trend for VAT, NVAT as well as associated costs for P1 and P2 in Table 9. The WT incurred for both six and twelve month periods were higher than the results for VAT. The resource utilisation (RU) of the machines and technicians over both simulation periods retained similar values as was generated for the one-month period.

Table 9: KPI for Six and Twelve Month Simulation Periods.

\begin{tabular}{|c|c|c|c|c|}
\hline Simulation Length & Six Months & Six Months & Twelve Months & Twelve Months \\
& & & P1 & P2 \\
\hline Product Types & P1 & P2 & 26.3 & 31.33 \\
\hline VAT [hrs] & 13.14 & 15.56 & 34.41 & 29.62 \\
\hline NVAT [hrs] & 17.57 & 13.49 & 62.07 & 65.62 \\
\hline WT [hrs] & 27.47 & 23.69 & 94.6 & 49.6 \\
\hline TP & 95.3 & 44.9 & 2.1 & 1.12 \\
\hline WIP & 2.02 & 0.86 & $\$ 7,188$ & $\$ 11,027$ \\
\hline VA Cost [TTD] & $\$ 3,581.50$ & $\$ 5,445.95$ & $\$ 1,376$ & $\$ 1,184$ \\
\hline Transfer Cost [TTD] & $\$ 702.89$ & $\$ 539.91$ & $\$ 13.55$ & $\$ 10.94$ \\
\hline
\end{tabular}


When the results of the existing simulations were analysed, findings revealed that there continued to exist a high WT incurred compared to the associated VAT and NVAT values per product. This was notably seen within the conveyor processes and especially in the inspection processes. This suggested that waste in the form of NVAT and specifically WT contributed to $72.60 \%, 71.50 \%$ and $74.45 \%$ on average of the total processing time for the periods one month, six month and twelve months.

Additional results from the simulation indicated bottlenecks within the manufacturing lines. Numerically, the injection moulding processes possessed WT from $58.80 \%$ to $66.32 \%$ whereas the inspection processes generated WT between $39.68 \%$ and $52.29 \%$ respectively. After further analysis, it was suggested that this high WT was a result of the inefficient utilisation of the technicians. By obtaining these results from the simulation, it was then paramount to devise methods for mitigating the bottlenecks that were found. Thus LM strategies were used to improve the efficiency and system performance of the PIM simulation models.

\section{Modifications and Improvements to the Existing Simulation}

\subsection{Lean Strategies}

After careful analysis was done on the results that were generated by the existing simulation models, strategies using lean manufacturing were devised for the purpose of mitigating the bottlenecks that contributed to the challenges faced. These strategies included Heijunka Methodology for improving batch production [11], Kanban to reduce inspection time [3], and Six Sigma for improving the CU within the PIM operations [20]. For the purpose of confirming where there existed greater potential for improvement of the existing model, What-if scenarios were used by combining these strategies subsequently. It was suggested that since each strategy targeted a specific challenge, the combinations of these improvements may have contributed to similar benefits when combined.

Heijunka, as a lean strategy was used to mitigate the challenge where the loss of four working cavities for the Husky 300 injection moulding machine incurred a loss of approximately TTD $\$ 229,000$ over a period of twelve months. Matzka, Mascolo and Furmans [14] defined Heijunka as a lean methodology that combined levelling and line balancing in production systems. After running the simulation models for all three periods, improvements were prevalent, notably for the total busy cost, which was the running cost incurred by the resources within the simulation models. For each period, there was an overall reduction in cost by approximately $\$ 8,000, \$ 102,000$ and $\$ 234,000$ respectively when the Husky 300 injection moulding machine was replaced by the Husky 120 machine.

To execute the second strategy using Kanban, the processing time was of the conveyor was adjusted to facilitate the processing time using imaging sensors for product inspection. By doing so, it eliminated the need for visual inspection to be conducted by technicians within the line. With this addition to the models, technicians would then be constantly scheduled to the injection moulding processes, thus reducing the WT for each product entering the simulation models. It was further noted that as these sensors were installed within the conveyor system, the standalone inspection process module that was implemented in the original framework and existing simulation models was instead integrated into the conveyor process to reflect the design of the actual system with greater accuracy.

The third strategy using Six Sigma aimed at increasing the CU of resources within the existing simulation models using an improved routing system [9]. In the actual system, the routing of raw material entering the PIM machines indicated that there was some loss in equilibrium between the CU for each production line. With this in mind, Six Sigma was applied to the simulation model 20]. The challenge within the routing system of the original manufacturing line highlighted bottlenecks when routing the raw material into the injection moulding machines. This was observed through the KPI from the results obtained for the existing simulation models. The main modification which transpired was the addition of a decision module that was called Smart Routing to simulate the Automated Material Handling System (AMHS). It followed the expression as shown in the following: 
If:
Injection Moulding Process 1.WIP $<17$ or
Inspect Product Line 1.WIP $<1]$
Route Product Type P1 or P2 to
Injection Moulding Process 1

Simulation results revealed a reduction in WT for the second injection moulding machine by $31.79 \%$ and an increase in VAT by $68.20 \%$ of the total time per product compared to that of the existing model which had a WT of $66.30 \%$ and a VAT of $33.69 \%$. Furthermore, there was an overall reduction in total busy cost by $56.38 \%$.

\subsection{Comparison of Simulation Results}

After each simulation model was run for the corresponding simulation periods, their results were subsequently analysed to compare with those obtained by the individual strategies earlier in this paper as well as to that of the existing models. Hence, the following graphical illustration, Fig. 4 highlighted the comparison of KPI between the existing models and the proposed strategies. These illustrations highlighted the comparative results of the twelve-month simulation period.

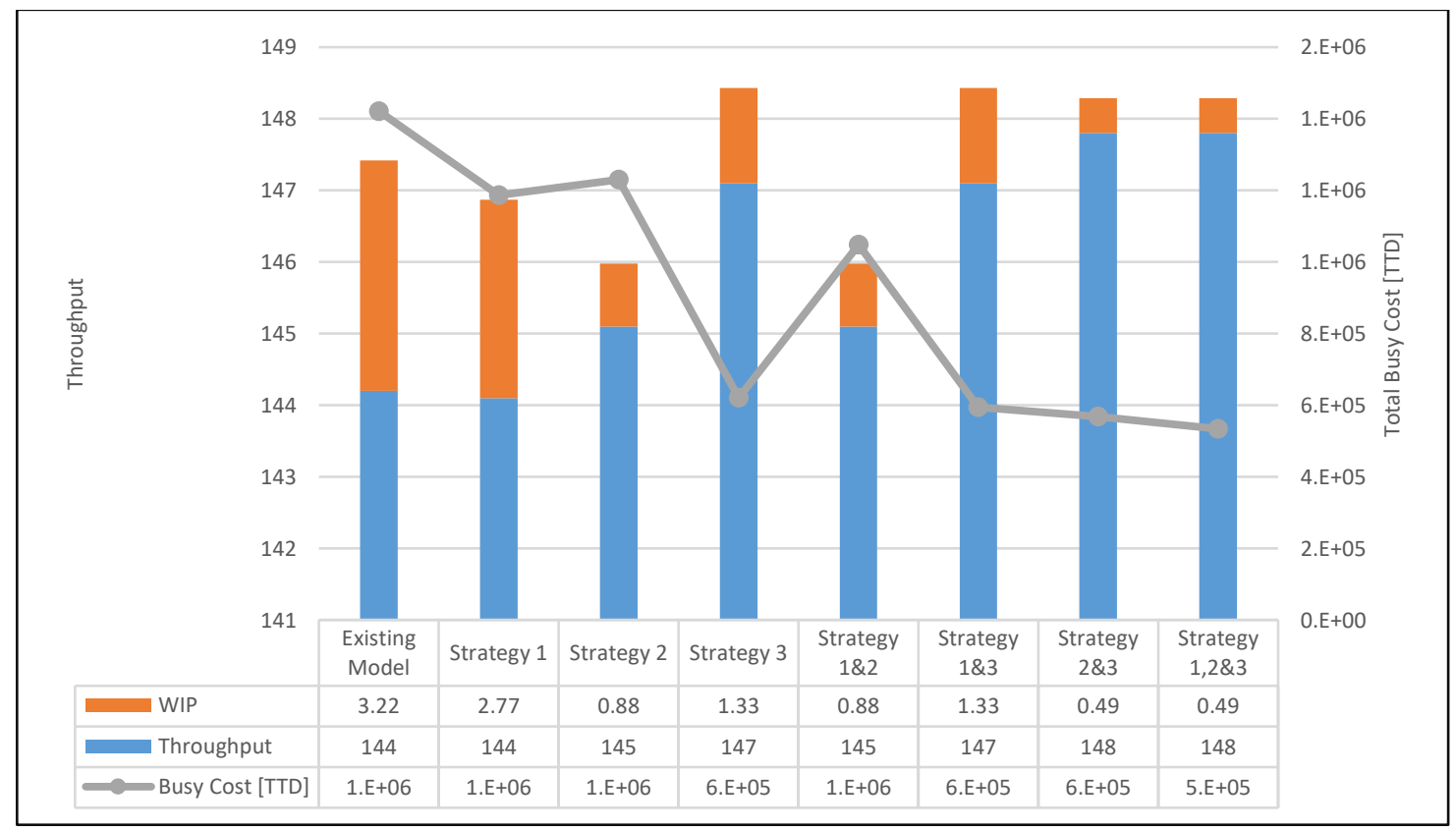

Figure 4: Comparison of KPI between Simulation Models.

\section{Financial Impact and Inferences}

The findings observed in this research paper thus far indicated the benefits of using LM strategies for improving system performance of PIM operations. In light of this, it was necessary to perform a cost-benefit analysis (CBA) if the company desired to implement these strategies into their PIM framework. In addition, understanding the return on investment (ROI) was another key facet to decide the feasibility in using the LM strategies for improvement of the system performance. From these calculations, Strategy Three not only possessed the fastest break even, where it indicated an ROI of $69.34 \%$ within the first year of initial investment, but the lowest $\mathrm{CBA}_{\mathrm{f}}$ of 0.59 . This meant that it was the most feasible LM strategy in the context of financial investment to be implemented into the company. 


\section{Conclusion}

In conclusion, the hypothesis of this research paper showed a positive relationship between the performance and cost incurred during PIM operations possessed notable relation with the resource utilization and how the processes were developed within the production line. In performing background research behind the SME within the global market, it was clear that there existed several challenges due to the prevalence of larger companies within the competitive world.

It was in this regard that findings revealed improvements in KPI where, over the twelve-month simulation period for example the existing model saw an improvement in its WIP by $84.78 \%$ using a combination of three LM strategies, improvements in its WT by $98.03 \%$ and a TP increase by $2.49 \%$. In terms of cost incurred by using the resources, the incorporation of an AMHS within strategy three reduced the usage cost by $37.55 \%$ which, based on the framework of the simulation would have saved the company a significant cost in RU. This, in combination with the $\mathrm{CBA}_{\mathrm{f}}$ of 0.59 and ROI of $69.45 \%$, which indicated a break-even in revenue within the first year of investment highlighted the benefits of utilizing lean thinking as a means of improving the PIM operations within the company.

\section{References}

[1] Abed, Seraj Yousef. 2008. "Improving Productivity in Food Processing Industries Using Simulation a Case Study." 12th WSEAS International Conference on Systems, Heraklion, Greece, July 23 - 25, 2008.

[2] Advanced, Production Systems. 2018. Injection Molding Cost. Lyndon, Kentucky: Advanced Production Systems.

[3] Bae, Ki-Hwan G., Lee A. Evans, and Alan Summers. 2016. "Lean Design and Analysis of a Milk-Run Delivery System: Case Study." 2016 Winter Simulation Conference, Washington, DC, USA, December 11-14, 2016.

[4] Chen, Wen-Chin, Gong-Loung Fu, Pei-Hao Tai, and Wei-Jaw Deng. 2009. "Process Parameter Optimisation for Mimo Plastic Injeciton Molding Via Soft Computing." Elsevier 36 (2):8. doi: 10.1016/j.eswa.2007.10.020.

[5] Chen, Wen-Chin, Manh-Hung Ngyuyen, Wen-Hsin Chiu, Te-Ning Chen, and Pei-Hao Tai. 2016. "Optimization of the Plastic Injection Molding Process Using the Taguchi Method, Rsm, and Hybrid Ga-Pso." The International Journal of Advanced Manufacturing Technology 83 (9-12):13. doi: 10.1007/s00170-015-7683-0.

[6] Dang, Xuan-Phuong. 2014. "General Frameworks for Optimization of Plastic Injection Molding Process Parameters." Elsevier 41:12. doi: 10.1016/j.simpat.2013.11.003.

[7] Faisal, KP, Falah Ummer, Hareesh K C, Munavir Ayaniyat, Nijab K, Nikesh P, and Jibi R. 2015. "Analysis and Simulation of Crankshaft Manufacturing Unit Using Arena." International Journal of Scientific and Research Publications 5 (2):7.

[8] Glassdoor. 2013. "Technician Salaries in Trinidad and Tobago." [Database for Company Reviews and Ratings], Last Modified December 22, 2013, accessed February 23. https://www.glassdoor.com/Salaries/trinidad-and-tobago-technician-salarySRCH_IL.0,19_IN227_KO20,30.htm.

[9] Groover, Mikell P. 2007. Automation, Production Systems, and Computer-Integrated Manufacturing. 3rd ed. New Jersey, United States: Prentice Hall; 3 edition.

[10] Heshmat, M., M. A. El-Sharief, and M. G. El-Sebaie. 2013. "Simulation Modeling of Production Lines: A Case Study of Cement Production Line." Journal of Engineering Sciences 41 (3):8.

[11] Huttmeir, Andreas, Suzanne de Treville, Ann van Ackere, Leonard Monnier, and Johann Prenninger. 2009. "Trading Off between Heijunka and Just-in-Sequence " International Journal of Production Economics 118 (2):7. doi: 10.1016/j.ijpe.2008.12.014.

[12] Jacobson, Jessica. 2015. "A Tale of Two Lines: Plastic Bottle Manufacturing Addresses Flexible, Dedicated Lines." Beverage Industry 107:2. 
[13] Kumar, Vimal, Pratima Verma, Onkar, Suraj Pratap Singh, and Jitendra Katiyar. 2016. "Facility and Process Layout Analysis of an Sme Using Simulation: A Case Study of a Manufacturing Company." 2016 International Conference of Industrial Engineering and Operations Management, Kuala Lumpur, Malaysia, March 8-10, 2016.

[14] Matzka, Judith, Maria Di Mascolo, and Kai Furmans. 2012. "Buffer Sizing of a Heijunka Kanban System." Journal of Intelligent Manufacturing 23 (1):11. doi: 10.1007/s10845-009-0317-3.

[15] Mohammed, Abdullah. 2017. "Don't Just Teach a Man to Fish: Are Our Caribbean Sme Policies Fundamentally Wrong? ." Technology news from T\&T, Last Modified December 11, 2017, accessed January 7. https://technewstt.com/sme-policies/.

[16] Russell, Suzana N., and Harvey H. Millar. 2014. "Competitive Priorities of Manufacturing Firms in the Caribbean." Journal of Business and Management 16 (10):10. doi: 10.9790/487X-161017282.

[17] Rymaszewska, Anna Dorota. 2014. "The Challenges of Lean Manufacturing Implementation in Smes." Benchmarking an International Journal 21 (6):15. doi: 10.1108/BIJ-10-2012-0065.

[18] Sundar, R., A. N. Balaji, and R. M. Satheesh Kumar. 2014. "A Review on Lean Manufacturing Implementation Techniques." 12th Global Congress on Manufacturing and Management, GCMM 2014, Vellore, India, 30 December, 2014.

[19] Toyota, ATLAS. 2018. Do You Know Your Average Forklift Cost Per Hour? Illinois, United States of America: Atlas Toyota.

[20] Ullah, M., A. M. Khan, R. Nawaz, and R. Akhtar. 2016. "Process Improvement for Pet Bottles Manufacturing Company Using Six Sigma Approach." Technical Journal 21 (11):9.

[21] Womack, James P., and Daniel T. Jones. 2003. Lean Thinking: Banish Waste and Create Wealth in Your Corporation. 2 ed. Michigan, United States of America: Free Press.

[22] Xu, Yingjie, QingWen Zhang, Weihong Zhang, and Pan Zhang. 2015. "Optimization of Injection Molding Process Parameters to Improve the Mechanical Performance of Polymer Product against Impact." The International Journal of Advanced Manufacturing Technology 76 (9-12):9. doi: 10.1007/s00170-014-6434-y.

[23] Zhou, Xuandao, Yun Zhang, Ting Mao, and Huamin Zhou. 2017. "Monitoring and Dynamic Control of Quality Stability for Injection Molding Process." Journal of Materials Processing Technology 249:8. doi: 10.1016/j.jmatprotec.2017.05.038. 